\title{
ACQUISITION OF 3D INFORMATION FOR VANISHED STRUCTURE BY USING ONLY AN ANCIENT PICTURE
}

\author{
Y. Kunii ${ }^{\text {a* R. Sakamoto }}{ }^{\mathrm{b}}$ \\ ${ }^{a}$ Department of Landscape Architecture Science, Tokyo University of Agriculture, \\ 1-1-1 Sakuragaoka, Setagaya-ku, Tokyo, 156-8502, Japan - y3kunii@ nodai.ac.jp \\ b CSS Engineering Co., Ltd., 1251 Kotta, Tama-shi, Tokyo, 206-0014, Japan
}

\author{
Commission V, WG V/2
}

KEY WORDS: Ancient Picture, Historical Structure, 3D Information, Two-Point Perspective, 3D Modeling

\begin{abstract}
:
In order to acquire 3D information for reconstruction of vanished historical structure, grasp of 3D shape of such structure was attempted by using an ancient picture. Generally, 3D information of a structure is acquired by photogrammetric theory which requires two or more pictures. This paper clarifies that the geometrical information of the structure was obtained only from an ancient picture, and 3D information was acquired. This kind of method was applied for an ancient picture of the Old Imperial Theatre. The Old Imperial Theatre in the picture is constituted by two-point perspective. Therefore, estimated value of focal length of camera, length of camera to the Old Imperial Theatre and some parameters were calculated by estimation of field angle, using body height as an index of length and some geometrical information. Consequently, 3D coordinate of 120 measurement points on the surface of the Old Imperial Theatre were calculated respectively, and 3DCG modeling of the Old Imperial Theatre was realized.
\end{abstract}

\section{INTRODUCTION}

Japanese cultural heritage includes many kinds of historical structures such as temples, shrines, and private houses (Agency for Cultural Affairs). Such heritage must be observed by landscape architects or researchers to conserve landscape assets. However, there are many vanished historical structures which were assumed some important role as a legacy of each region. Typical reasons of the vanishing of such structures in Japan are some natural disasters which are earthquake, typhoon, mudslide, and so on. In order to grasp the past appearance of the vanished structures, extant drawings or pictures are useful information. Therefore, utilization of the ancient picture for the vanished structure was considered in this paper. The photogrammetric theory can be applied by using multiple pictures (Gruen, et al., 2004), however acquisition of the ancient multiple pictures for same structure is not possible.

In these circumstances, acquisition of 3D information for vanished structure by using only an ancient picture was investigated. Therefore, grasp of 3D shape of the vanished structure was proposed, and the method will be became useful tool for reconstruction of fundamental landscape.

\section{ANCIENT PICTURE OF OLD IMPERIAL THEATRE}

An ancient picture of the Old Imperial Theatre was applied in this paper. The Old Imperial Theatre was built in 1911, Chiyoda-ku, Tokyo, and some western cultures were accepted for the construction. After that, the theatre was scraped in 1965 due to aging, and actual one was built in 1966. Figure 1 shows the ancient picture which is owned by Japanese National Diet Library, and application in this paper was accepted. Some information for the picture (e.g. year, person, and camera) could not be grasped. Therefore, acquisition of 3D information for the theatre was attempted with such limited information.

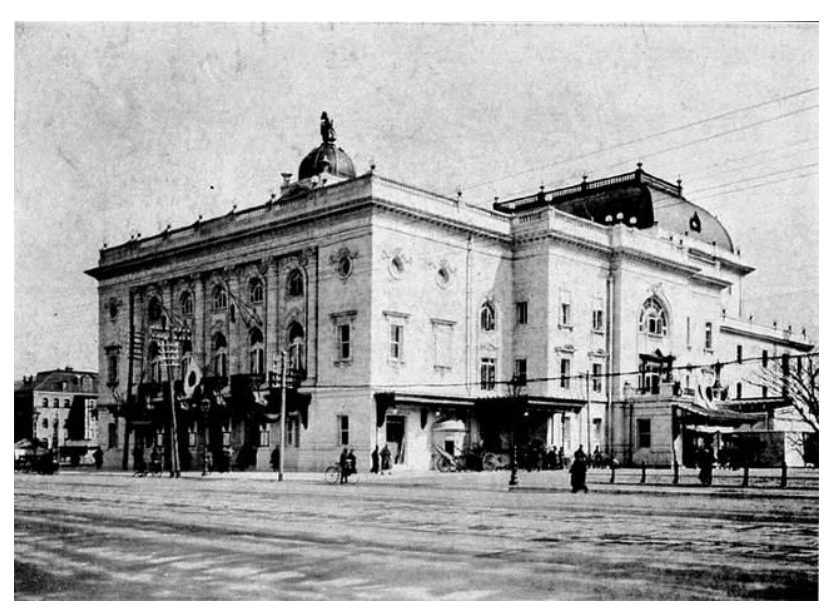

Figure 1. Old Imperial Theatre

\section{ACQUISITION OF 3D INFORMATION}

Generally, in order to acquisition of 3D information by using photogrammetric theory, multiple images for measurement object are used. However this paper investigates 3D measurement method by using only one ancient picture (Saegusa and Chikatsu, 2004). The detail procedures of the method are as follows.

\subsection{Calculation of Vanishing Points}

In order to acquire 3D information from single image, acquisition of depth $(Z)$ coordinate is became important problem. Therefore, this paper assumed that the ancient picture is constituted by two- 


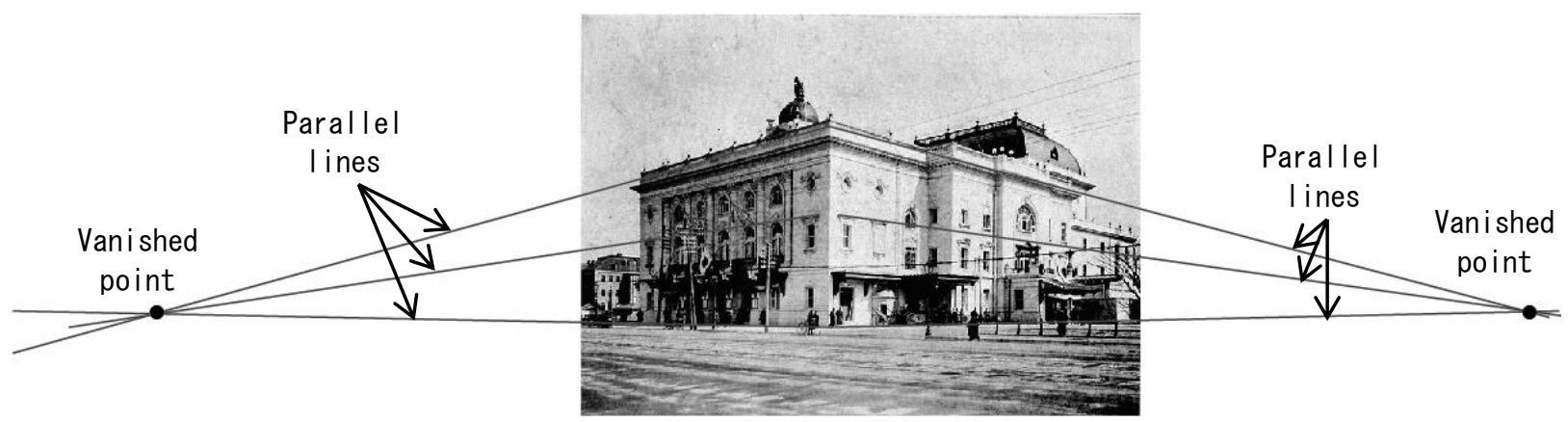

Figure 2. Estimation of vanished points

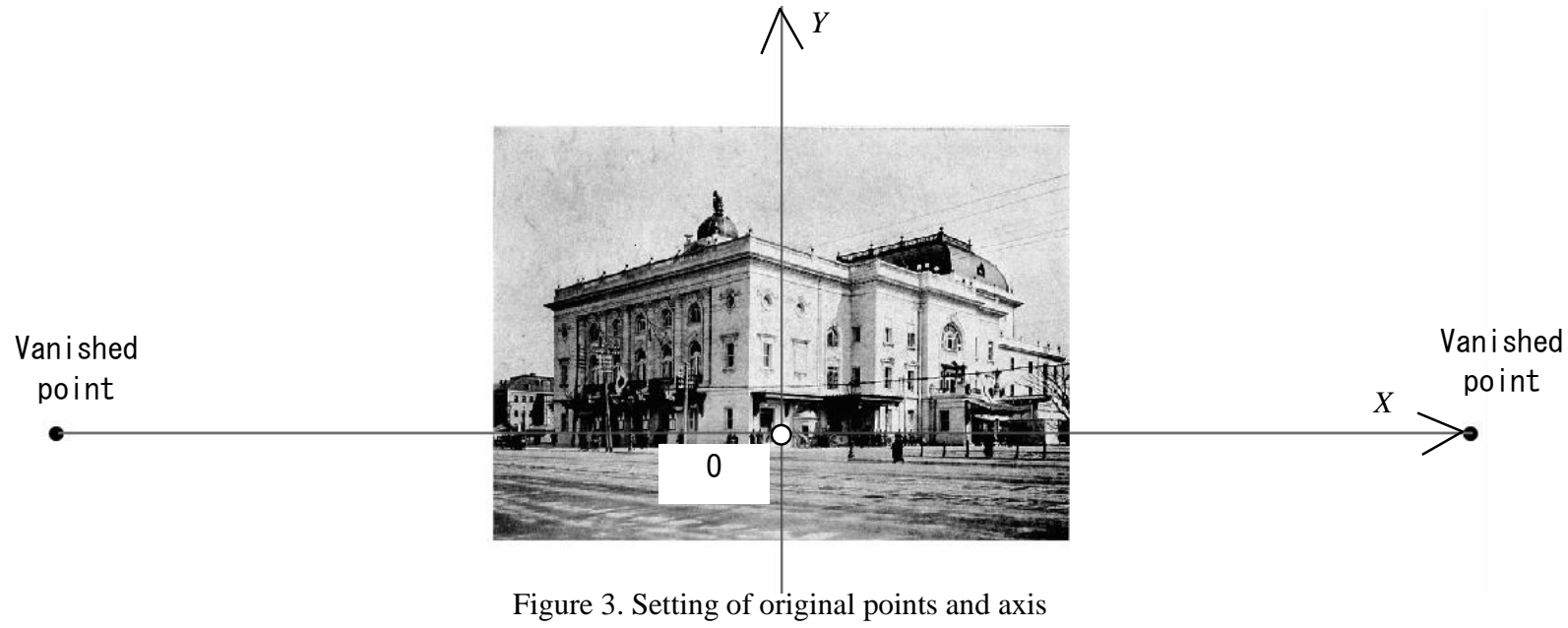

point perspective, and two vanishing points were calculated. The calculated vanishing points are shown in figure 2 .

\subsection{Acquisition of Image Coordinates}

The original point and coordinate system was set as shown in figure 3. $Y$ coordinate was set as center line, and $X$ coordinate was set as varnished line. Moreover, image coordinates for many feature points on the theatre (wall, post, window, and some objects) were obtained by manually. Consequently, 120 measurement points were obtained.

\subsection{Estimation of Focal Length}

Focal length is should be obtained for calculation of depth by using two vanishing points. Generally, focal length can be

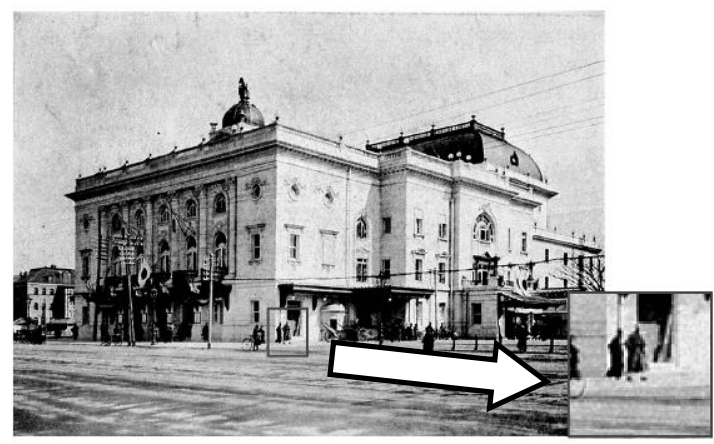

Figure 4. Index as body heght obtained by specification of each camera, however a device of taking the ancient picture could not be understood. Therefore, the focal length $(f)$ was estimated by width $(w)$ and angle $(\theta)$ of picture with following equation.

$$
f=\frac{w}{\tan \theta}
$$

\subsection{Calculation of Depth and Plane Length}

In order to calculate actual 3D coordinate by this method, actual index on the picture is required. Therefore, body height of a man who walk in front of the theatre was applied as an index (figure 4). His height was assumed as $1.55 \mathrm{~m}$ which is average value of Japanese male in Taisho era (1912-1926) (Matsuda, 2003). A geometric relation of camera, picture and the man are shown in figure 5 , and relation of depth length $(Z)$, focal length $(f)$, height of the man $(L)$ and height on the picture $(l)$ are expressed

\section{Theatre}

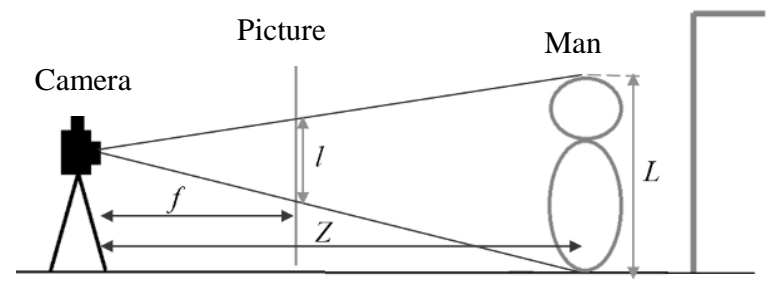

Figure 5. Geometric relation of camera, picture and man

following equation. 


$$
Z=\frac{f \cdot L}{l} \quad \cdots(2)
$$

Therefore, above equation was applied for all measurement points, and 120 depth lengths were calculated respectively.

In addition, 3D coordinate of the camera position was assumed by theory of two-point perspective (figure 6), and plane lengths $(X, Y)$ of all measurement points were also calculated. Consequently, acquisition of 3D coordinate of these 120 measurement points (figure 7) were realized, and 3D modeling of the theatre was performed.

\section{RESULTS AND REMARKS}

The 3D modeling for the theatre was performed by using these calculated 3D coordinates. 3D model of some parts (e.g. roof, wall and window) were prepared by using the 3D data, and 3D model was constructed by using such parts and coordinates (Kunii

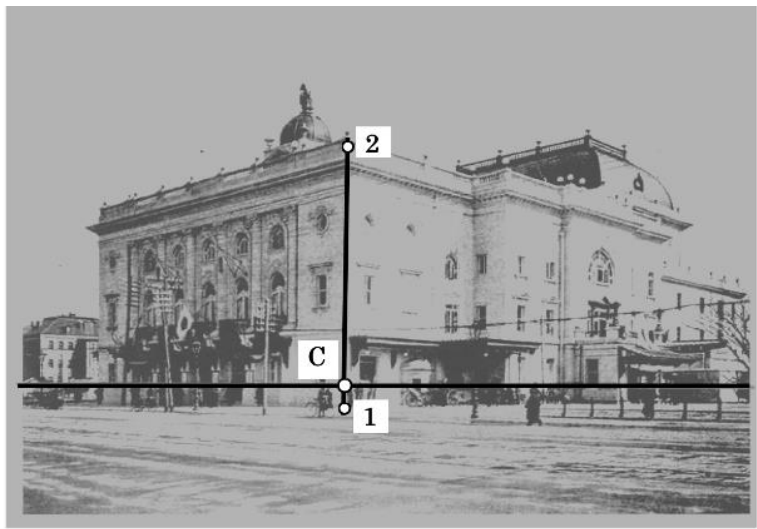

Figure 6. Estimation of camera position and Kaneko, 2011). Figure 8 shows the 3D model from some angle of view.

In addition, in order to confirm accuracy of the 3D coordinates, actual miniature model of the theatre was measured. The miniature model is owned by Tsubouchi Memorial Theatre Museum in Waseda University, and reconstructed by $1 / 50$ scale. For such miniature, 6 lengths that shown in figure 9 were measured, and compared with the length by acquired 3D coordinate with proposal method. As a result of the comparison, standard deviation of residual error was calculated $\pm 4.4 \mathrm{~m}$. The principal causes of the error were as follows;

- Using only limited information of the ancient picture

- As an index of actual coordinate by the body height of man.

- Comparison with miniature model.

Therefore, it seems that acquisition of accurate 3D information by using the proposal method was difficult. Nevertheless, approximate coordinate and shape could be grasped, and recreate of fundament and some landscape construction can be applied.

\section{CONCLUSIONS}

This paper investigates 3D information for vanished structure by using only an ancient picture. As a result, 3D coordinate of 120 measurement points on the surface of the Old Imperial Theatre were calculated respectively, and 3DCG modeling of the theatre was realized.

For further work, the proposed method needs be improved that some estimation values should be became accurate values. Moreover, in order to apply many ancient picture, application to some kinds of perspective method will be proposed. If this can be achieved, the proposed method will become a useful and convenient tool for 3D measurements of vanished historical structures.

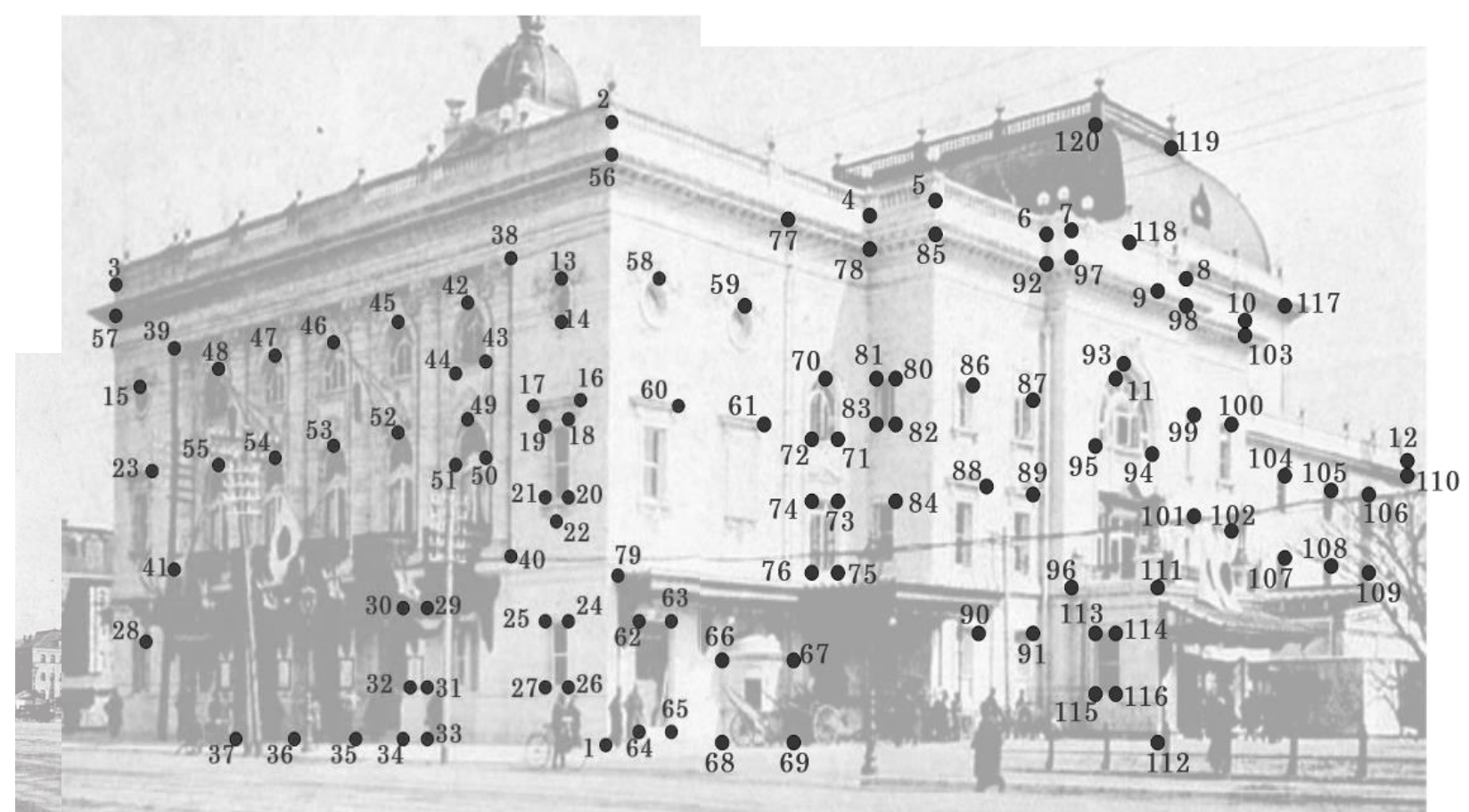

Figure 9. Compared length and direct $n$

Figure 7. Measurement points on the picture 


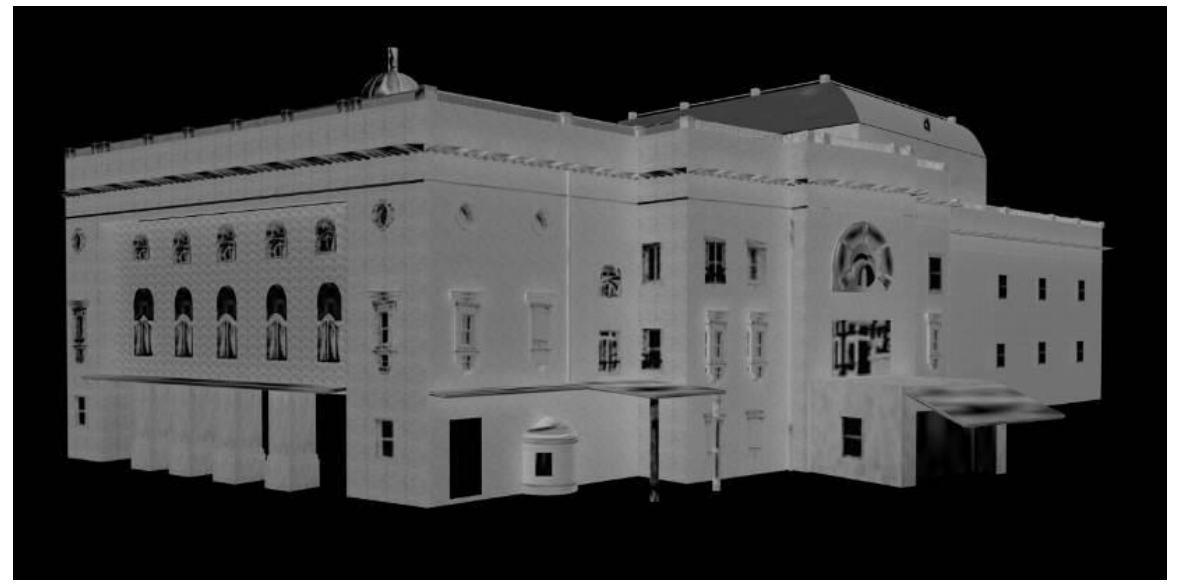

(a) Front side

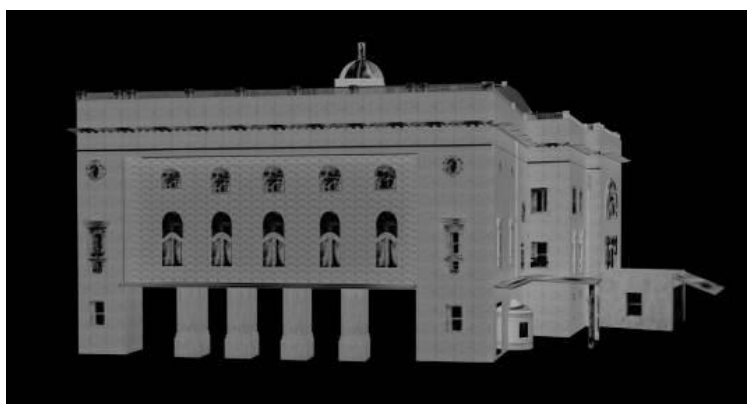

(b) Left side

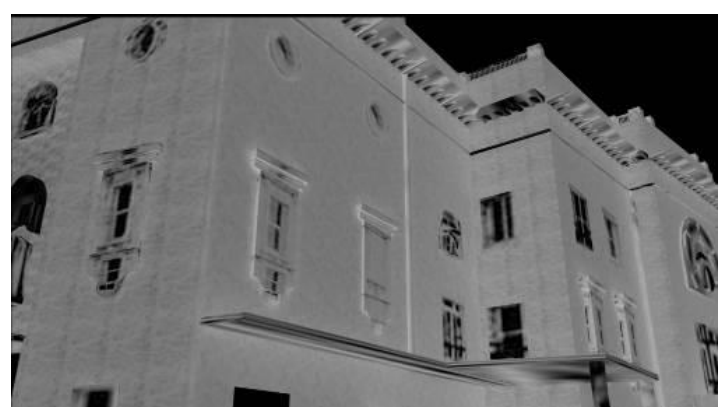

(c) Close up

Figure 8.3D modeling

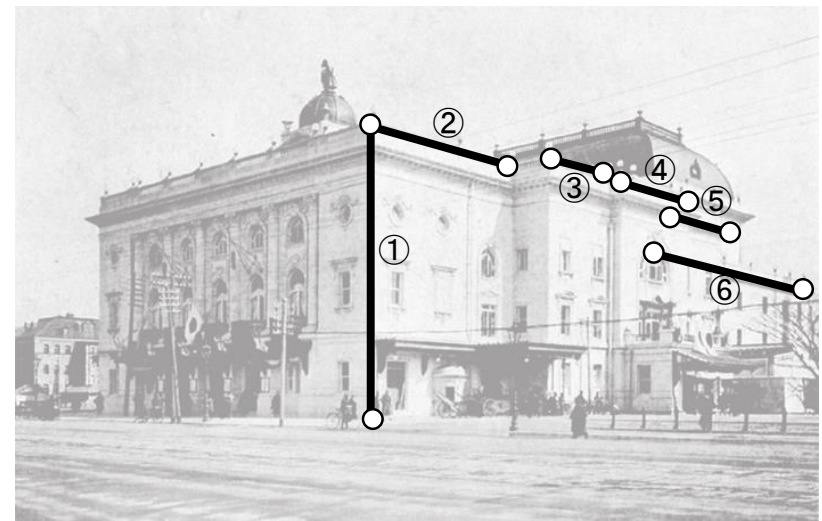

Figure 9. Compared length between proposal method and direct measurement

\section{ACKNOWLEDGEMENTS}

This investigation was supported by JSPS KAKENHI Grant Number 16K08133. And I would like to offer my special thanks to Japanese National Diet Library and Tsubouchi Memorial Theatre Museum in Waseda University.

\section{REFERENCES}

Agency for Cultural Affairs http://www.bunka.go.jp/english/ (17 Apr. 2016)

Gruen, A., Remondino, F., Zhang, L., 2004. Photogrammetric reconstruction of the Great Buddha of Bamiyan, Afghanistan. The Photogrammetric Record, 19(107), pp.177-199.

Kunii, Y., Kaneko, E., 2011. Investigation by 3D Modeling of Landscape for "Nihon-Odori" soon after the Opening of Yokohama Port. Journal of Agriculture Science, Tokyo University of Agriculture, 56(2), pp.162-170.

Matsuda, H., 2003. A Study of Japanese Heights in The MeijiTaisho-Pre War Showa Period - Human Height as an Indicator of Quality of Life -. The Review of Agricultural Economics, Hokkaido University, 59, pp.69-79.

Saegusa, T., Chikatsu, H., 2004. 3D Modeling and Representation of "Ideal City" Painted by Piero Della Francesca. ISPRS Archives, Vol. XXXV, Part B8, pp.153-156. 